\title{
Diamond-Like Carbon Film Deposition Using DC Ion Source with Cold Hollow Cathode
}

\author{
E. F. Shevchenko, ${ }^{1}$ V. A. Tarala, ${ }^{2}$ M. Yu. Shevchenko, ${ }^{1}$ and A. A. Titarenko ${ }^{1}$ \\ ${ }^{1}$ Scientific Educational Center of Nanotechnologies, North-Caucasus Federal University, Stavropol 355029, Russia \\ ${ }^{2}$ Southern Scientific Center of Russian Academy of Sciences, Rostov-on-Don 344006, Russia \\ Correspondence should be addressed to E. F. Shevchenko; e.shevchenko@mail.com
}

Received 9 May 2013; Accepted 5 November 2013; Published 23 January 2014

Academic Editor: Maria Loi

Copyright (C) 2014 E. F. Shevchenko et al. This is an open access article distributed under the Creative Commons Attribution License, which permits unrestricted use, distribution, and reproduction in any medium, provided the original work is properly cited.

\begin{abstract}
Carbon diamond-like thin films on a silicon substrate were deposited by direct reactive ion beam method with an ion source based on Penning direct-current discharge system with cold hollow cathode. Deposition was performed under various conditions. The pressure (12-200 $\mathrm{mPa}$ ) and the plasma-forming gas composition consisting of different organic compounds and hydrogen $\left(\mathrm{C}_{3} \mathrm{H}_{8}, \mathrm{CH}_{4}, \mathrm{Si}\left(\mathrm{CH}_{3}\right)_{2} \mathrm{Cl}_{2}, \mathrm{H}_{2}\right)$, the voltage of accelerating gap in the range $0.5-5 \mathrm{kV}$, and the substrate temperature in the range 20 $850^{\circ} \mathrm{C}$ were varied. Synthesized films were researched using nanoindentation, Raman, and FTIR spectroscopy methods. Analysis of the experimental results was made in accordance with a developed model describing processes of growth of the amorphous and crystalline carbon materials.
\end{abstract}

\section{Introduction}

Film deposition or surface modification directly from the ion beam is one of the most promising methods because it allows controlling the energy of the particles of deposited material and has a number of advantages over the other most common methods of producing films in vacuum [1-4]. At an average energy of the ions, $1-5 \mathrm{keV}$, the deposition method of immersion ion implantation is implemented [5-7]. For obtaining ions with such energy it is convenient to use selfcontained ion source based on DC glow discharge plasma allowing to regulate the ion energy and ion current density precisely and widely. Research to improve technology and equipment to carry out this process are very relevant in view of the accelerated development of micro- and nanoelectronics today.

Deposition of diamond-like carbon films [8] by the above-mentioned methods using multicellular ion source (IS) "Radical-M250" [3] is known. This IS forms the ion beam with a large area of cross section. To solve the same technological challenges, we proposed [9] to use the IS based on Penning discharge with hollow cathode in crossed $\mathrm{E} \times \mathrm{H}$ fields. Used modification of this type of IS cannot produce ion beams of large cross-sectional area; however, it has a number of advantages over other parameters. Unlike IS "RadicalM250" in the proposed IS there is independent adjustment of the ion current density and ion energy in a wide range. Furthermore, FWHM of function of ion energy distribution in the beam of IS "Radical-M250" is 540-580 eV [3]; the same parameter at the same beam current in proposed IS can be sufficiently lower [10]. Providing a significant influence of the ion energy on properties of the synthesized films, the ion source with a narrow energy spectrum of the ions will more effectively and predictably control the properties of the synthesized films. In comparison with a deposition system based on standard filament-type cathodes such as Kaufman type IS $[1,11]$, the proposed cold cathode system has longer operating life in a reactive plasma.

The purpose of this study was to investigate an influence of the deposition conditions on the characteristics of amorphous carbon films obtained with the help of the ion source based on reflective discharge with hollow cathode. 


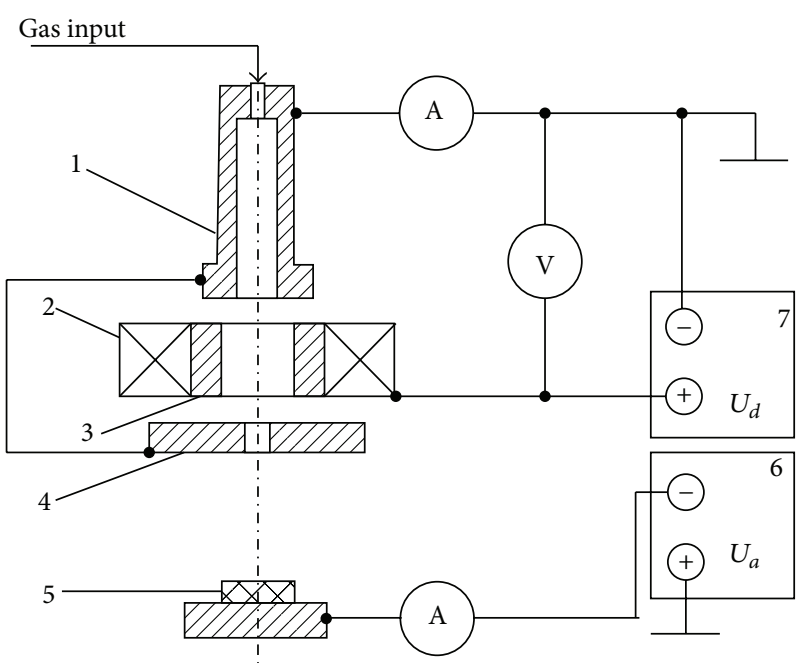

FIGURE 1: Schematic diagram of the reactive ion-beam deposition system. 1: hollow cathode; 2: magnet; 3: anode; 4: reflector cathode; 5: substrate; 6,7 : power supply sources.

\section{Experiment}

2.1. Experimental Setup. Figure 1 shows a schematic diagram of the reactive ion-beam deposition system. Ions were generated in the plasma of reflex-discharge which was excited in the discharge chamber formed by hollow cathode 1 with an inner diameter of $4 \mathrm{~mm}$ and a depth of $32 \mathrm{~mm}$ and cylindrical anode 3 with an inner diameter of $12 \mathrm{~mm}$ and reflector cathode 4 with an emission aperture about $4 \mathrm{~mm}$ in diameter. The magnetic field of $\approx 80 \mathrm{mT}$ in the discharge chamber was created by annular magnet 2 . The electrodes of the discharge chamber were cooled by running water. Through the hole in the cathode-reflector, ions penetrate into the accelerating gap and are accelerated by the electric field in the direction of the substrate 5 .

Accelerating voltage $U_{a}$ was regulated in the range of $0.5-$ $5 \mathrm{kV}$ by the power source 6 . Energy of extracted ions in this case can be evaluated as follows:

$$
E_{(i) n}=\alpha \cdot U_{d}+n \cdot U_{a} \pm \Delta E_{n},
$$

where $U_{d}$ is a hollow cathode discharge voltage (350-400 V) from the power source $7, \alpha \approx 0.8$ for this type IS, $n=1$ - ion charge and $\Delta E_{n}$ is blurring of $n$th peak of the energy spectrum of the ions. Moreover, during the deposition of dielectric film without charge neutralizer, the ion energy can be partially reduced due to uncompensated ionic charge arising both in the vacuum volume and around the growing surface. Plasma-forming gas propane $\left(\mathrm{C}_{3} \mathrm{H}_{8}\right)$ was let into the hollow cathode. In some experiments, which will be discussed separately, the plasma-forming gases methane $\left(\mathrm{CH}_{4}\right)$, dimethyldichlorosilane $\left(\mathrm{Si}\left(\mathrm{CH}_{3}\right)_{2} \mathrm{Cl}_{2}\right)$, and propanehydrogen mixtures $(1: 3)$ were used. Pumping of the vacuum chamber was made by turbomolecular pump TMN-1500 (3) to the minimal pressure of $2 \mathrm{mPa}$. Gas flow rate $Q$ was regulated in the range of $1.3-5 \mathrm{~m}^{3} \times \mathrm{mPa} / \mathrm{s}$. Calculations show that under these gas flow rates and used geometry the pressure in the discharge chamber was $0.8-3.4 \mathrm{~Pa}$. The source

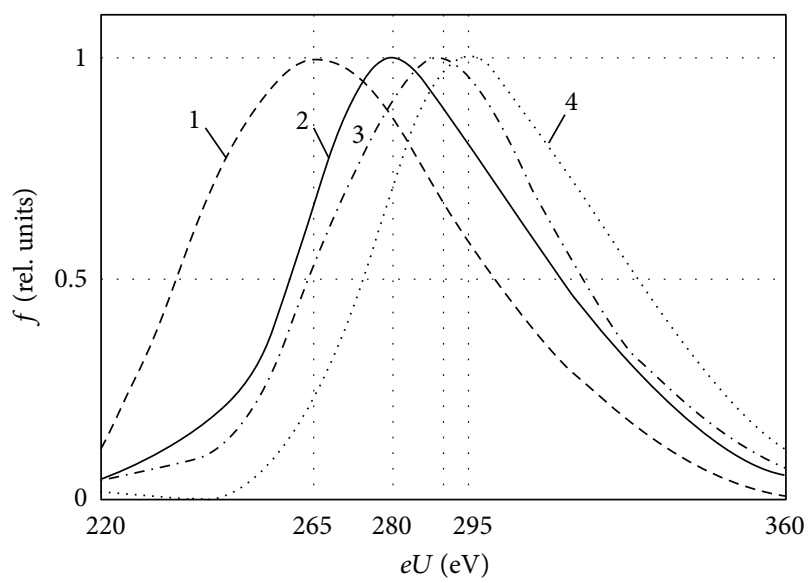

Figure 2: The energy spectra of ions of different gases. 1: dimethyldichlorosilane; 2: air; 3: propane; 4 : argon; $I_{d}=0.2 \mathrm{~A}, Q=$ $2.4 \mathrm{~m}^{3} \times \mathrm{mPa} / \mathrm{s} . \Delta E, \mathrm{eV}: 1: 64 ; 2: 53.5 ; 3: 56 ; 4: 55$.

operated continuously. Taking into consideration some of the features of this source on hydrocarbons $[9,12]$, the discharge current was maintained in the range of relatively small values of $60-80 \mathrm{~mA}$; the ion beam $I$ current to the substrate was of $35-70 \mathrm{~mA}$. To study the energy spectra of extracted ions at work on hydrocarbons and organ silicon compounds, the technique with a multigrid energy analyzer probe described in our previous studies [12] was used. Argon and atmosphere air were used as "control" gases in this study. Figure 2 shows obtained energy spectra.

The width of each spectrum at half-height of $\Delta E$ in all cases did not exceed a few tens of $\mathrm{eV}$. The most $\Delta E$ was observed at the dimethyldichlorosilane flow.

The substrate of monocrystalline silicon KEF-4.5 (100) was set at a distance of $12 \mathrm{~cm}$ from the ion source. Before the synthesis of the film the substrate cleaning was performed for 5 minutes with argon ions at $U_{a}=3.5 \mathrm{kV}, I=40 \mathrm{~mA}$ and $p=12 \mathrm{mPa}$. The temperature of uncooled substrate during the deposition did not exceed $250^{\circ} \mathrm{C}$ with the exception of experiments with heating of the substrate which will be discussed separately. Deposition time was 20 minutes.

The synthesized films were researched using Renishaw inVia Raman Microscope $(\lambda=514.5 \mathrm{~nm})$, nanoindenter Nanoscan-01, and FTIR spectrometer FSM-1201.

\section{Results and Discussion}

3.1. Results. Carbon film synthesis experiments at the maximal acceleration voltage $\left(U_{a}=5 \mathrm{kV}\right)$ showed that, at pressure $12.5 \mathrm{mPa}$ or less, synthesis of the film does not occur. Deposition failed also at $p=20 \mathrm{mPa}$ and $U_{a}=1.5 \mathrm{kV}$. Apparently, this is due to the advent of the uncompensated ion charge on the growing surface. The electric field of this charge prevents further flow of ions on the growth surface, which hinders the growth of the film. At these values of pressure and voltage the compensation of charge with the help of electrons from lowdensity ionized ion-beam plasma [13] is not sufficient. 


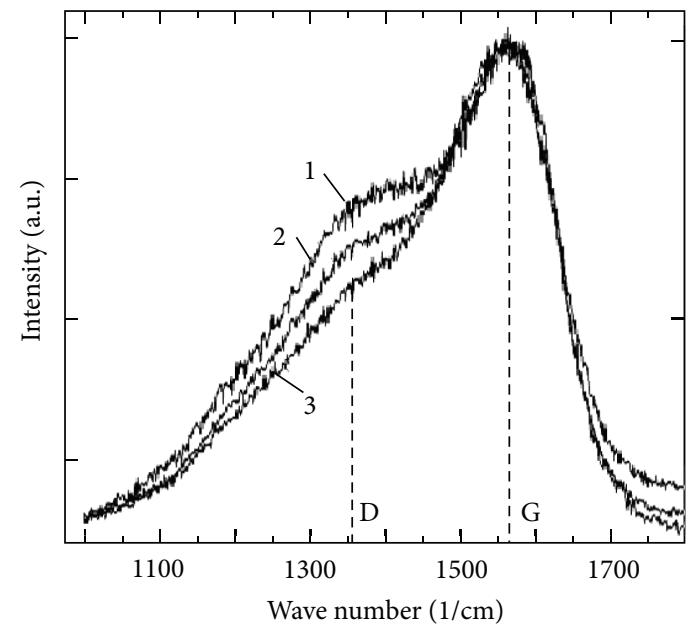

(a)

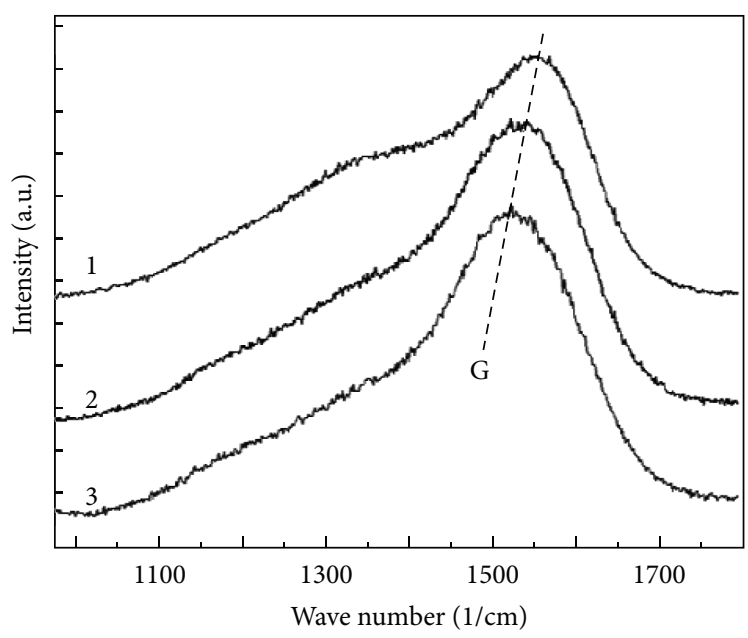

(b)

Figure 3: Raman spectra of samples. (a) $U_{a}=5 \mathrm{kV}$ and different pressure $p$, mPa: $1: 42 ; 2: 30 ; 3: 20$, and different substrate current $I$, mA: 1 : $70 ; 2: 45 ; 3: 35$; (b) $p=30 \mathrm{mPa}, U_{a}, \mathrm{kV}: 1: 5 ; 2: 3 ; 3: 1.5$.

Increase of gas pressure leads to the formation of carbon films with different structures and properties. Analysis of the Raman spectra (Figure 3(a)) shows that with increase of pressure the intensity of D-band $\left(1350 \mathrm{~cm}^{-1}\right)$ increases. In this case, $\mathrm{G}$ band $\left(\sim 1575 \mathrm{~cm}^{-1}\right)$ does not move, but the ratio of the intensity of bands $I_{\mathrm{D}} / I_{\mathrm{G}}$ increases, which, according to the data of $[14,15]$, indicates structural changes in the carbon film, followed by a higher content of $\mathrm{sp}^{2}$ hybridized carbon. The spectra of the films obtained under the same conditions but with an overlap of methane or dimethyldichlorosilane as the plasma-forming gases had no pronounced differences. Only the D and G bands of carbon were observed, and the band associated with phonon interactions of silicon carbide was absent.

Onto heating substrates $\left(600,700\right.$, and $\left.850^{\circ} \mathrm{C}\right)$ in the range of discussed accelerating voltages and gas pressures were deposited films, the Raman spectra of which have a $\mathrm{D}$ peak with a higher intensity $\left(I_{\mathrm{D}} / I_{\mathrm{G}}=0.7-0.9\right.$ rel. units $)$ compared with the samples synthesized without the heating. This fact indicates the increasing proportion of $\mathrm{sp}^{2}$ hybridized carbon and hence the film graphitization. Besides the gas pressure the accelerating voltage has significant influence on the film Raman spectra. With increasing $U_{a}$ from 1.5 to $5 \mathrm{kV}$ a transition of G band from 1540 to $1565 \mathrm{~cm}^{-1}$ was observed (Figure 3(b)). In addition, there is the increase of $I_{\mathrm{D}} / I_{\mathrm{G}}$ at $U_{a}>2.5 \mathrm{kV}$. These observations indicate substantial changes in the composition and structure of the synthesized films [16].

Study of hardness of the samples depending on the accelerating voltage (Figure 4(a)), the gas pressure (Figure 4(b)), and the substrate temperature confirm the results of research based on the Raman spectra. Regarding the effect of accelerating voltage on the hardness of the films, it was found that the samples synthesized at approximately $U_{a}=3 \mathrm{kV}$ have the highest values of hardness.

As seen in Figure 4(b), with raising pressure the hardness of the films decreases from $27 \mathrm{GPa}$ to $3 \mathrm{GPa}$; that is, the structure of the film changes from diamond-like to graphitelike. The decrease of hardness with increasing accelerating voltage occurs due to an increase of the fraction of $\mathrm{sp}^{2}$ carbon and/or due to an increase in the concentration of chemically bounded hydrogen within the film. When methane was used as a working gas, the hardness of films was slightly increased. The films synthesized at high temperatures had low hardness (up to $3 \mathrm{GPa}$ ); it allows characterizing them as graphite-like.

Analysis of the samples by Fourier transmission IR spectroscopy showed two significant areas of the chemical bonds vibrations. At $1000-1800 \mathrm{~cm}^{-1}$ we can observe the field of deformational vibrations of $\mathrm{C}-\mathrm{H}$ bonds, valence vibrations of carbonyl bonds, segregate $\mathrm{C}-\mathrm{C}$, and double $\mathrm{C}=\mathrm{C}$ bonds. Analysis in the valence area of vibrations of C-H bonds (2800-3200 $\mathrm{cm}^{-1}$, Figure 5, spectrum 1) showed a low concentration of chemically bounded hydrogen in the synthesized films. Meanwhile, at increase of the gas pressure $40-200 \mathrm{mPa}$ and/or reducing of the ion energy (accelerating voltage $U_{a} \leq 1 \mathrm{kV}$ ), the intensity of valence vibrations of $\mathrm{C}-\mathrm{H}$ bonds increases sharply (Figure 5, spectrum 2). These observations correspond to the increase of the chemically bounded hydrogen concentration in the film. Using a $\mathrm{C}_{3} \mathrm{H}_{8}: \mathrm{H}_{2}$ mixture up to $75 \%$ of volume of hydrogen has no significant effect on the intensity of the IR absorption bands of $\mathrm{C}-\mathrm{H}$ bonds. The IR spectrum 2 in the area of C$\mathrm{H}$ bonds valence vibrations has the following details: $\mathrm{sp}^{3}$ $\mathrm{CH}_{3}$ (a) (2960), sp $\mathrm{CH}_{2}$ (a) (2925), sp $\mathrm{sp}^{3} \mathrm{CH}(\mathrm{a})$ (2900), $\mathrm{sp}^{3}$ $\mathrm{CH}_{3}(\mathrm{~s})$ (2870), $\mathrm{sp}^{3} \mathrm{CH}_{2}$ (s) (2850), and $\mathrm{sp}^{3} \mathrm{CH}$ (s) (3030) (here $\mathrm{sp}^{3}, \mathrm{sp}^{2}$, and $\mathrm{sp}$ : hybridization type, the figures in brackets: wave number in $\mathrm{cm}^{-1}$, (a) and (s): asymmetric and symmetric vibrations). Absorption band of 3000 and $3045 \mathrm{~cm}^{-1}$ correspond to the valence vibrations of $\mathrm{sp}^{2} \mathrm{CH}$ and aromatic groups, respectively. The intensity of the IR absorption bands is directly related to the concentration of $\mathrm{CH}_{n}$ vibrational groups, which allows us to estimate the concentration of bounded hydrogen in the film $[17,18]$. 


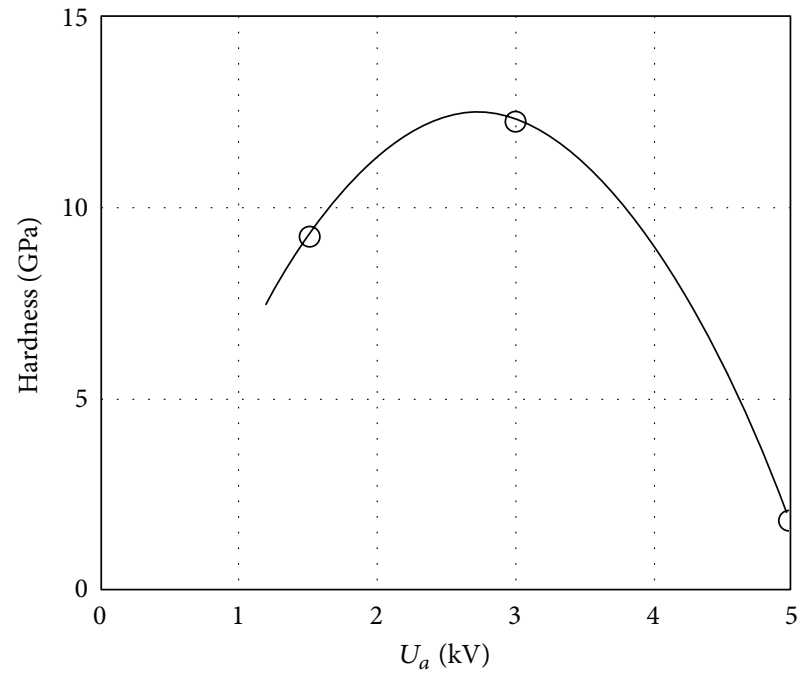

(a)

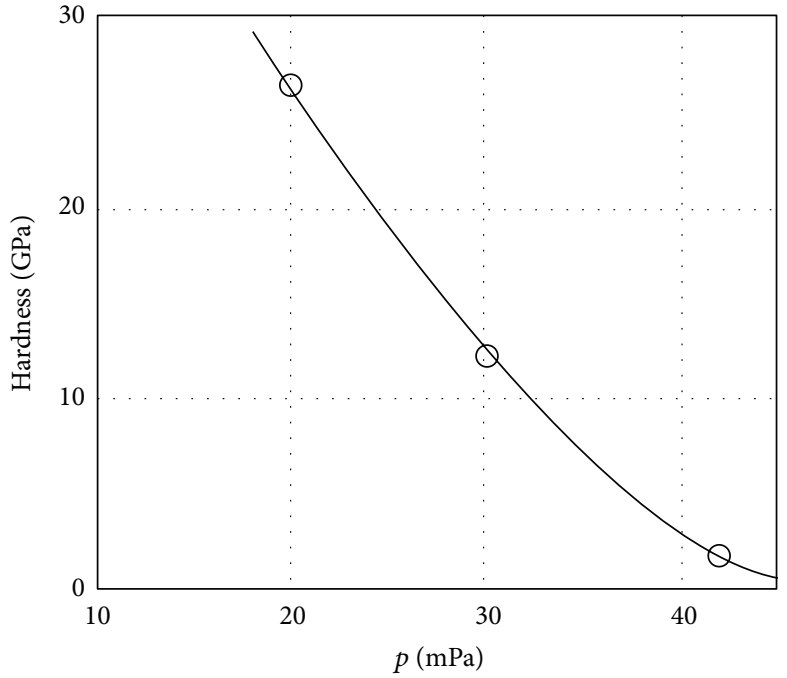

(b)

FIGURE 4: Dependence of the film hardness on the accelerating voltage at a fixed gas pressure $p=30 \mathrm{mPa}$ (a) and the gas pressure at a fixed acceleration voltage $U_{a}=5 \mathrm{kV}(\mathrm{b})$.

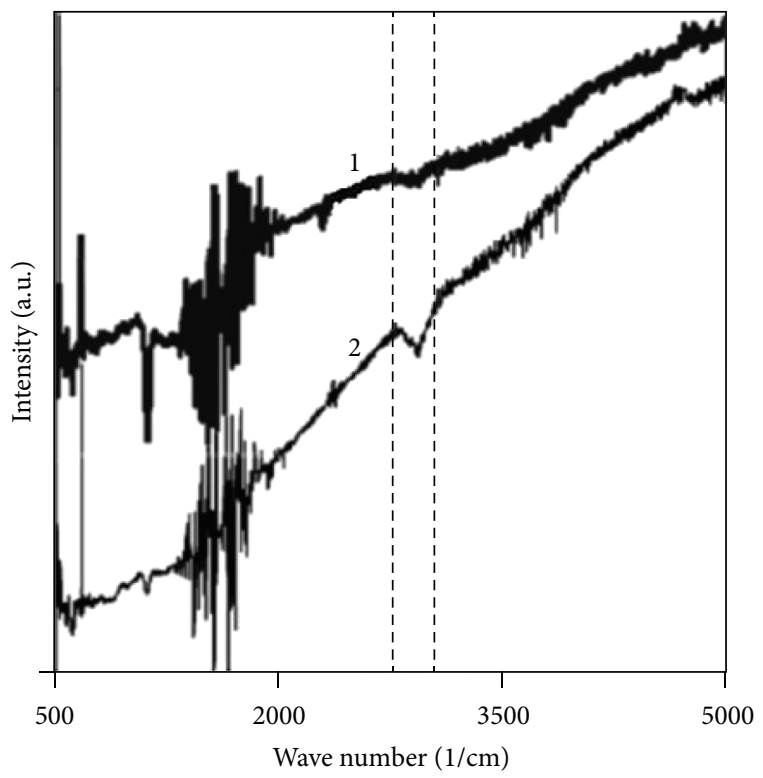

FIGURE 5: IR transmission spectra of films synthesized at $U_{a}=5 \mathrm{kV}$ and $p=20 \mathrm{mPa}(1)$ and $U_{a} \approx 0.5 \mathrm{kV}, p=200 \mathrm{mPa}$ (2).

This experimental research shows that with increase of the accelerating voltage and/or decrease of the pressure the intensity of IR light absorption in the range of stretching vibrations of $\mathrm{C}-\mathrm{H}$ bonds decreases. It was estimated that decrease of bounded hydrogen is from 10 to $2 \%$. Under these experimental conditions films with the high hydrogen content $>35 \%$, which can be categorized as hydrogenated polymer-like [19], were not synthesized.

There is another feature of deposited samples that was observed at FTIR analysis. The intensity of transmittance of red and infrared light for some samples was three times higher compared to the same parameter for the pure $\mathrm{Si}$ substrate. This fact points to one of possible technical applications. These films can be employed as antireflective coatings in IR sensors.

3.2. Discussions. The observed changes in the hardness and the content of bounded hydrogen, depending on the synthesis conditions, can be explained by the model of nucleation and growth of amorphous and crystalline carbon films [20]. According to this model, during the deposition of the film two types of clusters are formed, which replicate and modify the surface structure of a monocrystalline substrate. Thus, clusters replicating can be formed only by carbon atoms with $\mathrm{sp}^{3}$ hybridization, but clusters modifying the structure may consist of carbon atoms with both $\mathrm{sp}^{2}$ and $\mathrm{sp}^{3}$ hybridization types. In addition, modifying clusters and carbon atoms of $\mathrm{sp}^{3}$ hybridization type can form more bonds with hydrogen than clusters formed by carbon atoms with $\mathrm{sp}^{2}$ type hybridization.

With increasing the pressure, the rate of formation of modifying clusters is reduced more than the rate of formation of replicating clusters. Within the modeling the rates of these processes can be represented in the following form:

$$
\frac{V_{M}}{V_{S}}=K_{0}\left[a \frac{K_{r} P}{1+K_{r} P}\right] \exp \left(+\frac{\Delta E}{k T}\right),
$$

where $V_{M}, V_{S}$ are the formation rates of modifying and replicating clusters on the surface superstructure; $\Delta E$ is the difference in the potential barriers to the formation of modifying and replicating clusters, the superstructure of the substrate surface (depending on the type of components (radicals) of which the formation of clusters come from); $K_{0}$ is ratio of constants of direct cluster formation reactions, modifying and replicating the surface superstructure of substrate (depending on the type of components (radicals) from which 
clusters are formed); $K_{\gamma}$ is coefficient of hydrocarbon radical adsorption on the surface of the silicon substrate; $p$ is partial pressure of hydrocarbon radicals; $k$ is Boltzmann constant; and $T$ is thermodynamic temperature.

This expression shows that the increase in pressure, together with the amount of active particles capable to form layers at interacting with the substrate, leads to increased concentration of clusters modifying the surface and hence to increase of the fraction of $\mathrm{sp}^{2}$ carbon. The increase in the fraction of $\mathrm{sp}^{2}$ carbon occurs irrespective of the reasons for increasing the number of active particles in the gaseous phase (plasma). Increasing number of $\mathrm{sp}^{3}$ clusters in the matrix changes the film structure from amorphous $(\mathrm{a}-\mathrm{C}: \mathrm{H})$ to tetragonal (ta-C:H) carbon and therefore leads to an increase in the hardness of the films, as observed in our experiments. Increase of the pressure leads to increase of the formation rate of both $\mathrm{sp}^{3}$ and $\mathrm{sp}^{2}$ carbon clusters, but the rate of formation of $\mathrm{sp}^{2}$ carbon is higher. Furthermore, at $p>100 \mathrm{mPa}$ and $U_{a}<1 \mathrm{kV}$, the changes in the composition of deposited films can be explained by the changes in the deposition conditions under which the accelerating gap ignites the gas discharge, the energy of bombarding ions is lowered, the concentration of hydrogen in products of propane dissociation increases, and the degree of destruction of propane is reduced.

As regards the influence of an accelerating voltage determining the ion energy, its role in the formation of the film structure can be described as follows. Increasing the accelerating potential leads to a greater role of the processes of destruction of clusters. In the first place, clusters with high potential energy are destroyed. In the case of the synthesis of amorphous films under ion bombardment surfacemodifying cluster predominantly form, and probability of destruction of cluster formed by $\mathrm{sp}^{3}$ carbon is higher than in the case of cluster formed by the $\mathrm{sp}^{2}$ hybridized carbon. As a result, with increasing acceleration of voltage in the result of competing of two processes of cluster formation and their destruction in the film, the ratio of carbon with $\mathrm{sp}^{3}$ hybridization type decreases. At the same time the proportion of bound hydrogen is reduced. Since cluster modifying the surface structure and formed by the two carbon atoms type with $\mathrm{sp}^{3}$ hybridization can form up to four bonds with hydrogen atoms, whereas with $\mathrm{sp}^{2}$ type only to two bonds, then the reduction in the proportion of $\mathrm{sp}^{3}$ carbon must be accompanied by a decrease of the concentration of bounded hydrogen. Thus, the intense ion bombardment during growth process is the main reason for the low content of bounded hydrogen in the films produced in this work. It should be noted that an increase of clusters in the matrix which modify the superstructure and which are formed by sp2 carbon atoms, leads to a changes in the film structure from amorphous polymer-like to the amorphous diamondlike, and finally, to the amorphous graphite. Such structural changes explain non-monotonic dependence of the film hardness on the accelerating voltage.

It should be noted that the increase of the concentration of $\mathrm{sp}^{2}$ carbon in the films with the increase of the accelerating voltage was also obtained in RF discharge plasma system with [21], in which the role of the accelerating voltage carries substrate bias $\left(U_{\text {bias }}\right)$. In the case of RF plasma system, samples with the highest hardness were obtained at pressures of $3.6 \mathrm{~Pa}$ and $U_{\text {bias }}=-400 \mathrm{~V}$, whereas in the case of synthesis with the help of IS, the conditions were different ( $p, T$, gas composition). In addition, the concentration of bound hydrogen in the films produced by the RF plasma system was significantly higher than in the case of ion beams usage. Meanwhile, dependencies of films hardness changes on alternating accelerating IS voltage, and substrate bias voltage with RF plasma system is similar. Similar hardness dependencies of synthesized films on the accelerating voltage and gas pressure were obtained in glow discharge plasma system [22]. Dependencies of refractive index and optical gap changes on ion energy are also similar for amorphous carbon films deposited by both RF plasma system and direct ion-beam system [11]. As it was showed in [3] the hardness, density, and electrical resistance of the films depend on the ion energy during the deposition. In this case, the hardness dependency on the ion energy is described by a curve with a maximum. Thus, under these circumstances, it can be concluded that at consistent change in the deposition parameters, regardless of the type of plasma source, the nature of effects of pressure and ion energy on the structure and composition of growing amorphous carbon films remains the same.

\section{Conclusions}

Deposition of carbon films with the help of plasma ion source with a hollow cathode DC discharge allows varying accurately and widely different deposition conditions: the pressure and the composition of the plasma-forming gas, current density, and ion energy. Films synthesized by this method may have both graphite-like and diamond-like material structures.

Since a dependence of the hardness and the content of bounded hydrogen from the pressure and the accelerating voltage (ion energy) was identified, then for the deposition of carbon films the source with narrow energy spectrum of ions should be used. Narrow energy spreading of ions generated by the source based on hollow cathode reflective discharge allows obtaining films with more exact defined characteristics.

\section{Conflict of Interests}

The authors declare that there is no conflict of interests regarding the publication of this paper.

\section{Acknowledgments}

The authors thank the colleagues from the North-Caucasus Federal University: Martens V. Y. for discussions and Kasharina L. A. for Raman spectroscopy measure. The project was made under financial support of Russian federal educational program (agreement no. 14.A18.21.1085). 


\section{References}

[1] A. V. Hayes, V. Kanarov, and B. Vidinsky, "Fifty centimeter ion beam source," Review of Scientific Instruments, vol. 67, no. 4, pp. 1638-1641, 1996.

[2] M. J. Paterson, K. G. Orrman-Rossiter, D. K. Sood, and S. K. Bhargava, "Structural investigation of low energy ion beam deposited diamond-like films," Diamond and Related Materials, vol. 2, no. 11, pp. 1439-1444, 1993.

[3] K. A. Valiev, "Reactive ion beam synthesis of thin films directly from ion beam," Physical Surface Engineering, vol. 1, no. 1, pp. 27-33, 2003.

[4] P. J. Fallon, V. S. Veerasamy, C. A. Davis et al., "Properties of filtered-ion-beam-deposited diamondlike carbon as a function of ion energy," Physical Review B, vol. 48, no. 7, pp. 4777-4782, 1993.

[5] A. André, "Physics of plasma-based ion implantation and deposition (PBIID) and high power impulse magnetron sputtering (HIPIMS): a comparison," Physica Status Solidi A, vol. 205, no. 4, pp. 965-970, 2008.

[6] A. Anders, Ed., Handbook of Plasma ImmersIon Ion ImplantatIon and DepositIon, John Wiley \& Sons, New York, NY, USA, 2000.

[7] K. Baba and R. Hatada, "Properties of diamond-like carbon films deposited on polymer substrates by plasma source ion implantation," in Proceedings of the 8th International Conference on Modification of Materials with Particle Beams and Plasma Flows (CMM '06), Tomsk, Russia, September 2006.

[8] J. Robertson, "DLC review," Materials Science and Engineering, vol. 37, article 135, 2002.

[9] V. Y. Martens, B. M. Sinelnikov, V. A. Tarala, and E. F. Shevchenko, "Ion source based on reflex-discharge with cold hollow cathode for reactive ion-beam synthesis of diamondlike films," in Proceedings of the 9th International Conference on Modification of Materials with Particle Beams and Plasma Flows (CMM '08), Tomsk, Russia, September 2008.

[10] N. V. Gavrilov, "Research of energy spectra of ions extracted from reflex discharge with hollow cathode," Izvestia Vuzov. Phisika, vol. 23, no. 3, pp. 124-126, 1980 (Russian).

[11] R. Locher, C. Wild, and P. Koidl, "Direct ion-beam deposition of amorphous hydrogenated carbon films," Surface and Coatings Technology, vol. 47, no. 1-3, pp. 426-432, 1991.

[12] V. Y. Martens and E. F. Shevchenko, "Analysis of a hollowcathode reflex discharge in a hydrocarbon flow," Technical Physics, vol. 55, no. 8, pp. 1134-1137, 2010.

[13] V. I. Farenik, "Receipt and transportation of ion beams of low and average energy," Physical Surface Engineering, vol. 3, no. 1-2, pp. 4-29, 2005.

[14] A. C. Ferrari and J. Robertson, "Interpretation of Raman spectra of disordered and amorphous carbon," Physical Review B, vol. 61, no. 20, pp. 14095-14107, 2000.

[15] C. Casiraghi, A. C. Ferrari, and J. Robertson, "Raman spectroscopy of hydrogenated amorphous carbons," Physical Review B, vol. 72, no. 8, Article ID 085401, 2005.

[16] A. C. Ferrari and J. Robertson, "Raman spectroscopy of amorphous, nanostructured, diamond-like carbon, and nanodiamond," Philosophical Transactions of the Royal Society A, vol. 362, no. 1824, pp. 2477-2512, 2004.

[17] M. H. Brodsky, M. Cardona, and J. J. Cuomo, "Infrared and Raman spectra of the silicon-hydrogen bonds in amorphous silicon prepared by glow discharge and sputtering," Physical Review B, vol. 16, no. 8, pp. 3556-3571, 1977.
[18] D. Sarangi, O. S. Panwar, S. Kumar, and R. Bhattacharyya, "Characterization studies of diamond-like carbon films grown using a saddle-field fast-atom-beam source," Journal of Vacuum Science and Technology A, vol. 18, no. 5, pp. 2302-2311, 2000.

[19] C. Casiraghi, F. Piazza, A. C. Ferrari, D. Grambole, and J. Robertson, "Bonding in hydrogenated diamond-like carbon by Raman spectroscopy," Diamond and Related Materials, vol. 14, no. 3-7, pp. 1098-1102, 2005.

[20] B. M. Sinel'nikov and V. A. Tarala, "Modeling and simulating the nucleation of amorphous or crystalline films of diamond-like materials," Russian Microelectronics, vol. 40, no. 8, pp. 578-586, 2011.

[21] B. M. Sinelnikov, V. A. Tarala, and T. N. Prohoda, "Synthesis and study of diamond-like carbon films produced by RF plasma from methane," Vestnik YuNC RAN, vol. 5, no. 2, pp. 120-123, 2009 (Russian).

[22] N. V. Gavrilov, A. S. Mamaev, and A. S. Kaigorodov, "Diamondlike a-C:H coatings deposited in a non-self-sustained discharge with plasma cathode," Technical Physics Letters, vol. 35, no. 1, pp. 33-35, 2009. 

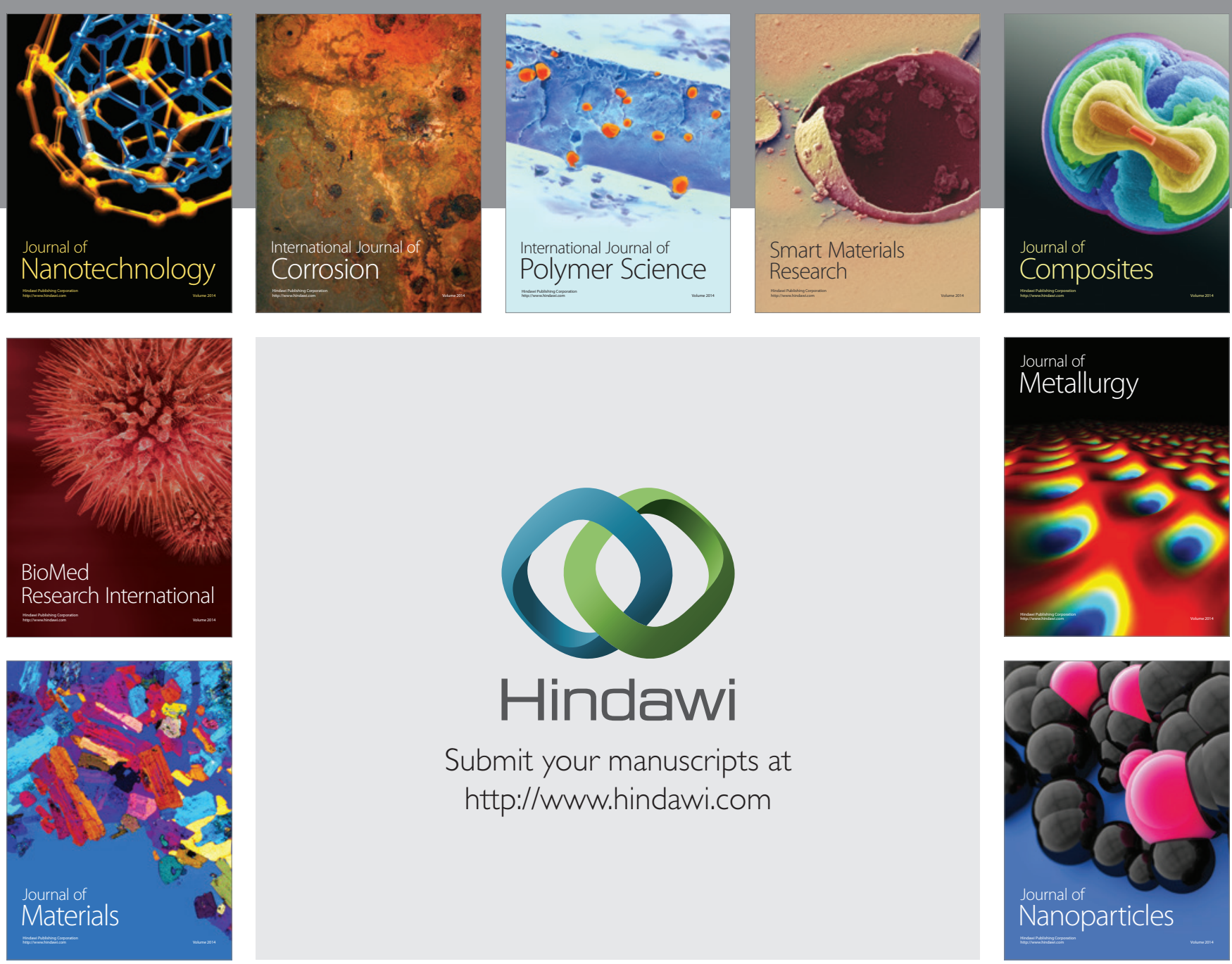

Submit your manuscripts at http://www.hindawi.com
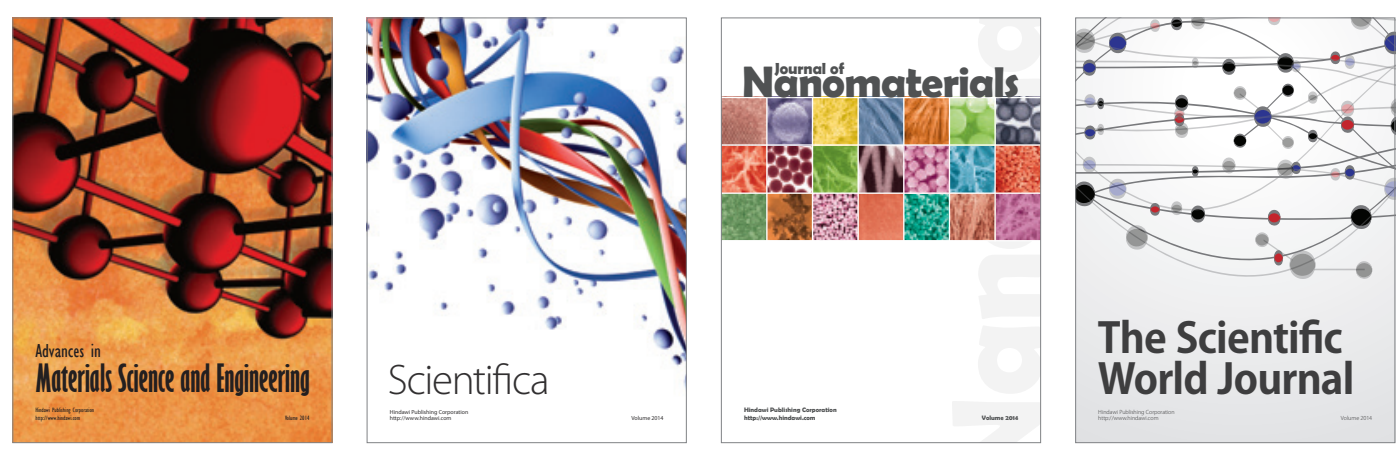

\section{The Scientific World Journal}
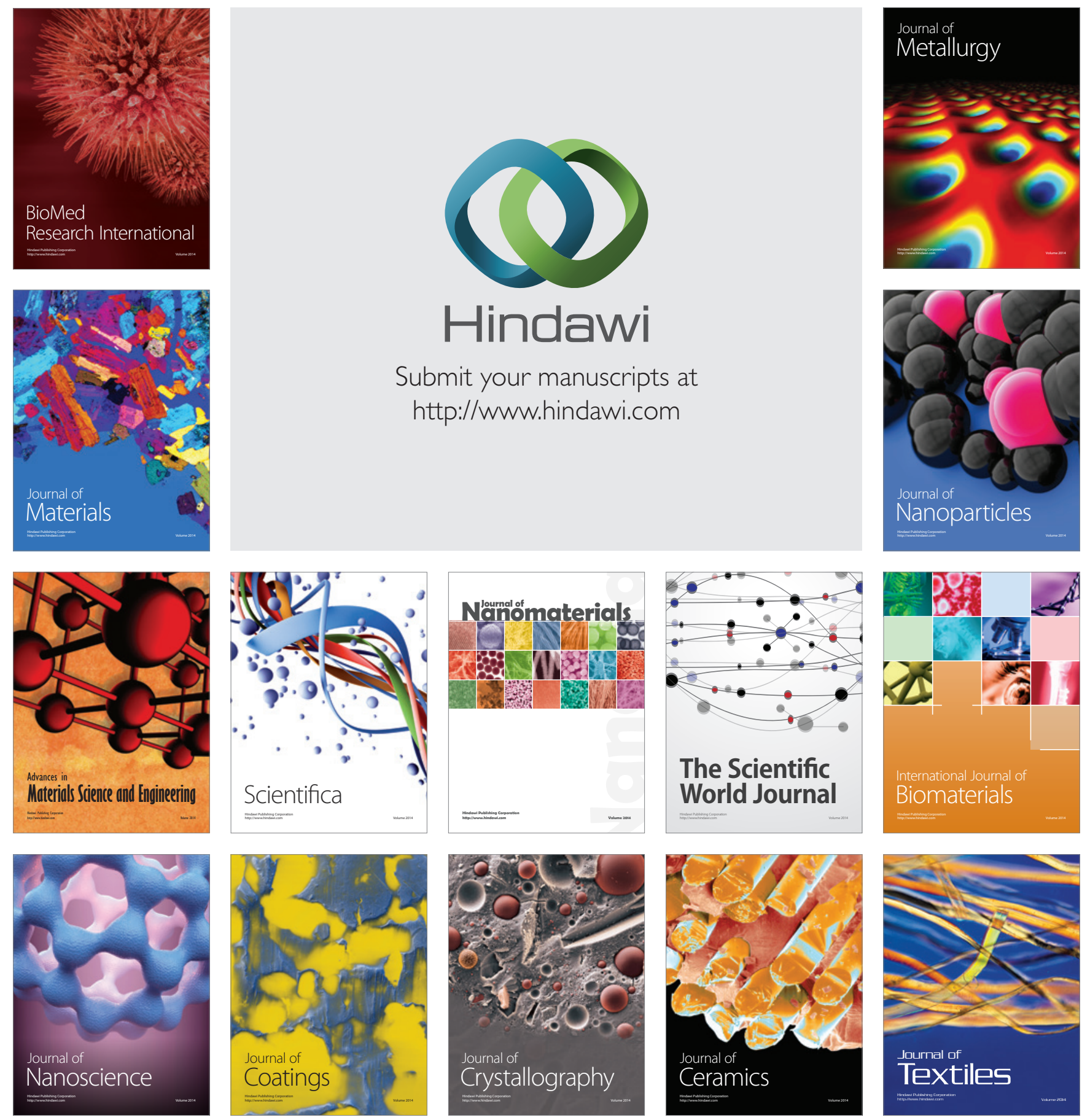